\title{
Hybrid Computation Scheme for the measurement of SAR in the complex characterization of human head exposure to EM Radiation
}

\author{
V. Rama Krishna Sharma ${ }^{1}$, Dr. Chandrasekhar Paidimarri ${ }^{2}$ \\ ${ }^{I}$ Associate Professor, ECE, Guru Nanak Institutions Technical Campus, Hyderabad. \\ ${ }^{2}$ Head,ECE,Osmania University, Hyderabad
}

\begin{abstract}
Scientists use the SAR (specific absorption rate) to determine the amount of radiation that human tissue absorbs. This measurement is especially important for mobile telephones, which radiate close to the brain. The model studies how a human head absorbs a radiated wave from an antenna and the temperature increase that the absorbed radiation causes. In view of the effects of electromagnetic radiation to human body, the influence of surrounding environment caused by EM radiation is always a serious problem. Also, parameters called body loss and perfusion rate are defined.
\end{abstract}

Keywords: Body loss, perfectly matched layers, Perfusion rate, Specific absorption rate.

\section{INTRODUCTION}

The introduction of the paper should explain the nature of the problem, previous work, purpose, and the contribution of the paper. The contents of each section may be provided to understand easily about the paper. The increasing use of wireless equipment has also increased the amount of radiation energy to which human bodies are exposed, and it is particularly important to avoid radiation into the brain. Experts continue to debate how dangerous this radiation might be. Almost everyone agrees, however, that it is important to minimize exposure to radiation. A common property that measures absorbed energy is the SAR value, calculated as, $\mathrm{SAR}=(/ \mathrm{E} / / \mathrm{E} /) / 2 \rho$. where $\sigma$ is the conductivity of human brain tissue, $\rho$ is the density, and $/ \mathbf{E} /$ is the norm of the electric field. The SAR value is an average over a region of either $10 \mathrm{~g}$ or $1 \mathrm{~g}$ of brain tissue, depending on national rules. This model does not calculate the average value and so it refers to the local SAR value. The maximum local SAR value is always higher than the maximum SAR value. Different positions of the antenna in the talking mode are compared, and the position with the antenna located on the bottom of the mobile handset and facing the head is recommended for minimal body loss [1,2]. With the large-scale application of mobile communications, the total amount of electromagnetic radiation will increase and people will have to re-evaluate the social effect of mobile communications. The influence of EM radiation will be one of the most important elements which should be considered in the research and design of mobile communications system [5].

\section{Em Wave Propagation Characterisation}

The radiation comes from a patch antenna placed on the left side of the head. A line current on an edge acts as an equivalent current source feeding the two patches of the antenna. To avoid reflections, the model makes use of PMLs (Perfectly Matched Layers). The model solves the vector-Helmholtz equation everywhere in the domain for a certain frequency.

\begin{tabular}{|l|l|l|}
\hline Frequency & Value & Description \\
\hline $835 \mathrm{MHz}$ & $1.35 \mathrm{~S} / \mathrm{m}$ & Conductivity \\
\hline $835 \mathrm{MHz}$ & 56 & Relative Permitivitty \\
\hline
\end{tabular}

This example takes material properties for the human brain from a presentation by $\mathrm{G}$. The following table reviews some important frequency-dependent properties in this publication. The interpolation function samples these values to create a realistic variation. switching method is adapted for co-located multi antenna systems to reduce the influence of the index finger on the antenna's efficiency[3] .

\section{HEATING OF THE HEAD}

The bioheat equation models the heating of the head with a heating loss due to the blood flow. This heat loss depends on the heat capacity and density of the blood, and on the blood perfusion rate. The perfusion rate varies significantly in different parts of the human body, and the table below presents the values used here. 


\begin{tabular}{lll}
\hline PART & \multicolumn{2}{l}{ PERFUSION RATE } \\
\hline Brain & $2 \cdot 10^{-3}$ & $(\mathrm{ml} / \mathrm{s}) / \mathrm{ml}$ \\
\hline Bone & $3 \cdot 10^{-4}$ & $(\mathrm{ml} / \mathrm{s}) / \mathrm{ml}$ \\
\hline Skin & $3 \cdot 10^{-4}$ & $(\mathrm{ml} / \mathrm{s}) / \mathrm{ml}$ \\
\hline
\end{tabular}

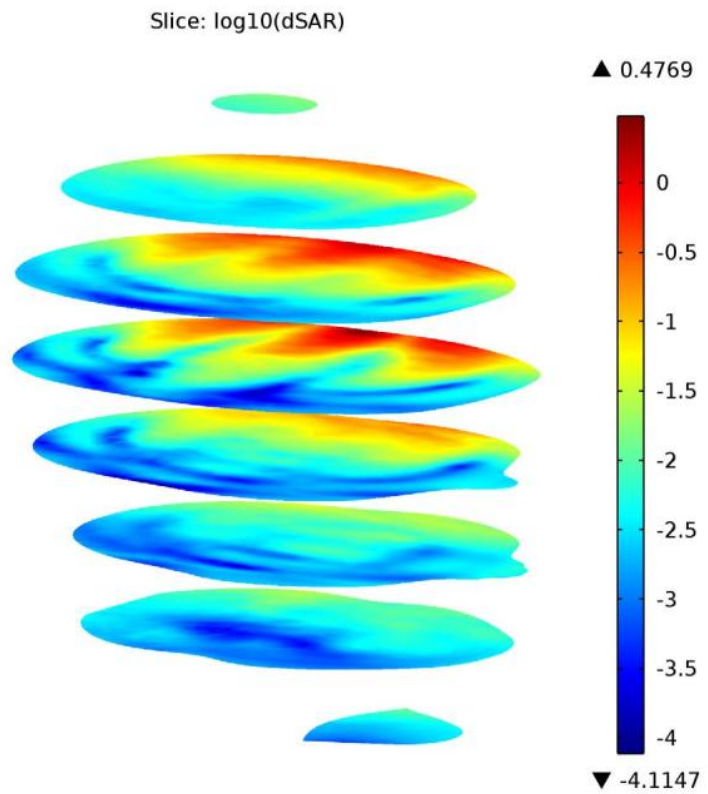

Figure 1: Log-scale slice plot of the local SAR value.

The same interpolation function used for the electric parameters also models the difference in perfusion rate between the brain tissue inside the head and the outer parts of skin and bone. Note again that the use of the interpolation function does not have any physical relevance; it is just to show a realistic effect of a varying material parameter.

\section{Simulation Results AND CONCLUSION}

The model studies the local SAR value in the head using the formula described earlier for the frequency $835 \mathrm{MHz}$. The SAR value is highest close to the surface of the head facing the incident wave. The differences in electrical properties become visible if you plot the local SAR value on a log scale (Figure 1). The bio-heat equation produces a similar plot for the heating of the head, which is highest closest to the antenna. The maximum temperature increase (from $37 \square \mathrm{C}$ ) is less than $0.2 \square \mathrm{C}$, and drops rapidly inside the head. When the antenna is mounted on the top of ground plane, the leftand-right-hand difference is due to the impact of the index finger, and when the antenna is mounted on the bottom of the ground plane, this difference is mainly caused by that the antenna is covered by different parts of hand phantom (either the bottom part of the thumb or the tip of the little finger) [4].

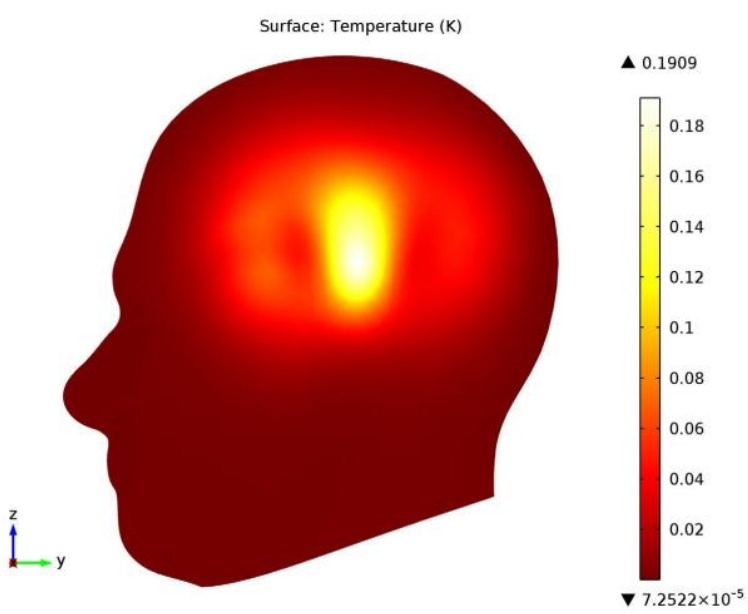

Figure 2: The local increase in temperature at the surface has a maximum of $0.193 \square C$ right beneath the antenna.

\section{REFERENCES}

[1] Ramli, K. N., R. A. Abd-Alhameed, C. H. See, P. S. Excell, and J. M. Noras, \Hybrid computational scheme for antenna-human body interaction," Progress In Electromagnetics Research, Vol. 133, 117\{136, 2013.

[2] Yu,W.,S.Yong, C.L. Tang, and D.Tu, \Accurate simulation of the radiation performance of a mobile slide phone in a hand-held position", IEEE Antennas Propag.Mag., vol.52,1680-1777,Apr.2010.

[3] Ramanchanran, P., Z. Milosavjevic, and C. Beckman, \Adaptive penta-band handset antenna with hand e®ect compensation,"IEEE Microwaves, Antennas \& Propagation, Vol. 6, No. 1, 79\{ 86, Jan. 2011

[4] Li, C.-H., E. O, N. Chavannes, E. Cherubini, H. U. Gerber, and Kuster, IEffects of hand phantom on mobile phone antenna 
performance," IEEE Trans. Antennas Propag., Vol. 57, No. 9, $2763\{2770$, Sep. 2009.

[5] V. Rama Krishna Sharma, Dr. Chandrasekhar paidimarri, Deepthi KVBL, "A novel method for the efficient reduction of TDD based Electromagnetic Asymmetry with demand based slot allocation scheme incorporating TD-SCDMA", IJSRP, Vol 3, Issue 5, May-2013

V APPENDIX

\begin{tabular}{|c|c|c|c|}
\hline Name & Expression & Description & \\
\hline epsilonr_pcb & 5.23 & $\begin{array}{l}\text { Permittivity for } \\
\text { antenna board }\end{array}$ & the patch \\
\hline $\begin{array}{l}\text { epsilonr0_br } \\
\text { ain }\end{array}$ & 56 & $\begin{array}{l}\text { Permittivity for } \\
\text { tissue }\end{array}$ & the brain \\
\hline sigma0_brain & $1.35[\mathrm{~S} / \mathrm{m}]$ & $\begin{array}{l}\text { Conductivity for } \\
\text { tissue }\end{array}$ & the brain \\
\hline rho_brain & $1.03 \mathrm{e} 3\left[\mathrm{~kg} / \mathrm{m}^{\wedge} 3\right]$ & Density of brain & tissue \\
\hline sdamping & $2 \mathrm{e}-4$ & Sampling parameter & \\
\hline edamping & $4 \mathrm{e}-4$ & Sampling parameter & \\
\hline soffset & $-1.0[\mathrm{~S} / \mathrm{m}]$ & Sampling parameter & \\
\hline eoffset & -50 & Sampling parameter & \\
\hline c_blood & $3639[\mathrm{~J} /(\mathrm{kg} * \mathrm{~K})]$ & Heat capacity of & blood \\
\hline rho_blood & $1000\left[\mathrm{~kg} / \mathrm{m}^{\wedge} 3\right]$ & Density of blood & \\
\hline odamping & $1.08 \mathrm{e}-6[1 / \mathrm{s}]$ & Sampling parameter & \\
\hline ooffset & $7.8 \mathrm{e}-4[1 / \mathrm{s}]$ & Sampling parameter & \\
\hline freq & $835[\mathrm{MHz}]$ & Frequency & \\
\hline
\end{tabular}

